\title{
Pengaruh Pembelajaran Kooperatif Small Group Discussion (SGD) Dengan Talking Stick Berbantuan Handout Terhadap Hasil Belajar Biologi Siswa Kelas VIII SMPN 5 Padang Panjang
}

\section{The Effect Of Cooperative Small Group Learning Discussion (SGD) With Handout- Helpful Stick Talking On The Study Of Biological Learning Class VIII SMPN 5 Padang Panjang}

\author{
Diyyan Marneli ${ }^{*}$, Sefernnita Natria Helvi ${ }^{2}$ and Eliwatis ${ }^{3}$ \\ ${ }^{123}$ Program Studi Pendidikan Biologi, IAIN Batusangkar, Sumatera Barat \\ *korespondensi: diyyanmarneli@iainbatusangkar.ac.id
}

\begin{abstract}
Abstrak
Tujuan penelitian ini adalah untuk mengetahui pengaruh pembelajaran kooperatif Small Group Discussion (SGD) dengan talking stick berbantuan handout terhadap hasil belajar Biologi siswa kelas VIII di SMPN 5 Padang Panjang. Jenis penelitian ini adalah penelitian kuantitatif dengan menggunakan metode eksperimen semu dengan rancangan penelitian randomized control group posttest-only design. Pengambilan sampel dilakukan dengan teknik random sampling, dan sampel yang terpilih adalah kelas VIII 1 sebagai kelas eksperimen dan kelas VIII 2 sebagai kelas kontrol. Berdasarkan hasil analisis data kuantitatif didapatkan hasil belajar Biologi siswa kelas VIII SMPN 5 Padang Panjang dengan menerapkan pembelajaran kooperatif Small Group Discussion (SGD) dengan talking stick berbantuan handout terhadap hasil belajar Biologi siswa Kelas VIII di SMPN 5 Padang Panjang lebih baik dari hasil belajar Biologi siswa yang menggunakan diskusi face to face relationship berbantuan handout. Pembelajaran kooperatif Small Group Discussion (SGD) dengan talking stick berbantuan handout terhadap hasil belajar biologi siswa Kelas VIII di SMPN 5 Padang Panjang dapat meningkatkan hasil belajar biologi siswa.
\end{abstract}

Kata Kunci: Handout, SGD, Talking Stick

\begin{abstract}
The purpose of this study was to determine the effect of cooperative learning Small Group Discussion (SGD) with the talking stick assisted by handouts, on Biology learning outcomes of class VIII students at Padang Panjang Middle School 5. This type of research is quantitative research using quasiexperimental methods and as a study design using a randomized control group posttest-only design. Sampling is done by random sampling technique, and the selected sample is class VIII 1 as the experimental class, and class VIII 2 as the control class. Based on the results of quantitative data analysis, Biology student learning outcomes were obtained by applying cooperative learning Small Group Discussion (SGD) with talking sticks assisted by handouts to Biology learning outcomes of Class VIII students, at Padang Panjang Middle School 5, better than Biology learning outcomes of students 'using face to the discussion face relationship assisted by handouts'. Cooperative learning Small Group Discussion (SGD) with a talking stick assisted by handouts can improve the biology learning outcomes of Class VIII students, at Padang Panjang Middle School 5.
\end{abstract}

Keywords: Handout, SGD, Talking Stick

\section{PENDAHULUAN}

Pembelajaran Biologi adalah salah satu komponen pembelajaran di sekolah yang sangat berperan penting dalam mengembangkan potensi siswa, mengembangkan keterampilan dan menyadarkan siswa akan pentingnya kelestarian alam dan tetap menjaga 
alam agar tetap berada dalam keadaan yang baik sehingga tidak terjadinya berbagai bentuk ganguan lingkungan. Dalam proses pembelajaran seorang guru tidak hanya menyampaikan materi saja, tetapi juga mampu membangkitkan semangat belajar siswa dan merencanakan kegiatan pembelajaran dengan baik. Selain itu usaha yang dilakukan oleh seorang guru Biologi agar tujuan pembelajaran tercapai dengan maksimal adalah dengan memvariasikan strategi pembelajaran sehingga siswa tidak jenuh dalam belajar. Menurut Ismawati dan Hindarto (2011) interaksi belajar mengajar yaitu interaksi yang berlangsung dalam suatu ikatan untuk tujuan pendidikan dan pengajaran. Mengajar adalah suatu kegiatan yang mempunyai tujuan dalam proses pembelajaran, kegiatan ini diarahkan untuk mencapai keterlaksanaan proses pembelajaran.

Berdasarkan hasil observasi dan wawancara kepada guru dan siswa bahwa terdapat beberapa permasalahan yang dialami oleh siswa diantaranya hasil belajar kognitif siswa pada pembelajaran Biologi masih rendah. Saat proses pembelajaran berlangsung, siswa takut mengajukan pertanyaan kepada guru. Pada sesi diskusi, hanya siswa-siswa tertentu saja yang terlibat yaitu siswa yang pintar berbicara, sedangkan siswa yang kemampuan berbicaranya menengah ke bawah tidak ikut terlibat dan hasil diskusi hanya dicatat serta disimpulkan saat pelajaran berakhir. Banyaknya masalah dalam proses belajar mengajar, menyebabkan banyak siswa tidak terlibat dalam pembelajaran. Interaksi antara siswa dengan guru dan antara siswa dengan siswa di dalam kelas tidak terjadi dengan baik. Selain itu, tidak adanya evaluasi yang digunakan untuk mengukur kemampuan siswa sehingga dapat mengakibatkan rendahnya hasil belajar siswa.

Berdasarkan hasil penelitian Christiani dan Mintohari (2014) melalui penerapan Metode Small Group Discussion proses pembelajaran menjadi berpusat pada siswa sehingga meningkatkan aktivitas siswa dalam proses pembelajaran. Adanya peningkatan aktivitas siswa tersebut dapat meningkatkan hasil belajar siswa karena siswa menjadi berperan aktif menemukan sendiri konsep pembelajaran yang hendak dicapai melalui langkah-langkah pembelajaran yang berpusat pada siswa. Selanjutnya Purwanti (2017) mengatakan bahwa penggunaan metode $S G D$ sangat membantu mahasiswa dalam memahami perkuliahan, dan mampu lebih mengaktifkan kegiatan mereka. Dengan diskusi pada kelompok kecil mereka menjadi lebih berani dalam bertanya, maupun berpendapat. Hal serupa juga dilaporkan bahwa SGD atau diskusi kelompok kecil adalah suatu proses yang teratur dengan melibatkan sekelompok siswa dalam interaksi tatap muka kooperatif yang optimal dengan tujuan 
berbagai infomasi atau pengalaman, mengambil keputusan atau memecahkan suatu masalah (Hasibuan dan Moedjiono, 2008).

Model pembelajaran talking stick menurut Suherman (2006) adalah metode pembelajaran bermain tongkat yaitu pembelajaran yang dirancang untuk mengukur tingkat penguasaan materi pelajaran oleh murid dengan menggunakan media tongkat. Menurut Suprijno (2011) model pembelajaran talking stick diawali dengan penjelasan guru mengenai materi pokok yang akan dipelajari. Siswa diberi kesempatan membaca dan mempelajari materi tersebut. Guru selanjutnya meminta kepada siswa menutup bukunya.

Penggunaan model pembelajaran talking stick membuat siswa lebih bersemangat dan lebih cepat mengerti, hal ini terlihat ketika siswa mendapat tongkat dan mendapat pertanyaan, siswa cenderung menjawab pertanyaan secara langsung dengan pemikirannya sendiri bahkan ada juga yang menjawab pertanyaan dengan mendemonstrasikan secara langsung tanpa diminta (Siregar, 2015). Model pembelajaran talking stick ini memperhatikan banyak anggota dalam tiap kelompok, dimana semakin sedikit jumlah anggota dalam setiap kelompok maka hasilnya akan lebih baik (Pambudi, 2017).

Handout merupakan salah satu bahan pelajaran yang dapat mengatasi persoalan siswa dalam menyediakan bahan pelajaran. Menurut Prastowo (2011) handout adalah bahan pelajaran yang sangat ringkas. Bahan ajar ini bersumber dari beberapa literatur yang relavan terhadap KD dan materi pokok yang diajarkan kepada peserta didik. Bahan ajar ini diberikan kepada peserta didik guna memudahkan mereka saat mengikuti pelajaran.Dengan demikian bahan ajar ini tentunya bukanlah suatu bahan ajar yang mahal melainkan ekonomis dan praktis.

Handout digunakan dalam penelitian ini karena tidak semua siswa memiliki sumber belajar berupa LKS sehingga dapat mengangu maksimalnya hasil belajar. Pemilihan handout dapat dijadikan sumber belajar siswa dan dapat membantu siswa dalam memahami pembelajaran. Selain itu guru lebih mudah membimbing siswa dalam belajar dan melalui handout siswa dapat menyimak materi yang disampaikan oleh guru dengan baik sehingga hasil belajar menjadi lebih baik. Tujuan penelitian ini adalah mengetahui pengaruh pembelajaran kooperatif Small Group Discussion dengan talking stik berbantuan handout terhadap hasil belajar biologi siswa kelas VIII SMPN 5 Padang Panjang. 


\section{METODE PENELITIAN}

Penelitian ini telah dilakukan di SMPN 5 Padang Panjang, Jenis penelitian ini adalah penelitian kuantitatif dengan menggunakan metode eksperimen semu. Menurut Sugiyono (2008) menjelaskan bahwa metode eksperimen dapat diartikan sebagai metode penelitian yang diinginkan untuk mencari pengaruh perlakuan tertentu terhadap yang lain melalui kondisi yang terkendali dan terkontrol, dengan rancangan penelitian randomized control groupposttest only design. Populasi dalam penelitian ini adalah siswa kelas VIII SMPN 5 Padang Panjangtahun pelajaran 2018/2019 yang terdiri dari 3 kelas yaitu VIII 1, VIII 2 dan VIII 3. Pengambilan sampel dilakukan dengan teknik random sampling, sampel yang terpilih adalahkelas VIII 1 berjumlah 30 siswa sebagai kelas eksperimen dengan menggunakan perlakuan dan kelas VIII 2 berjumlah 27 siswa sebagai kelas kontrol tanpa menggunakan perlakuan. Data yang digunakan adalah data kuantitaif dari kedua kelas dengan pretestpostest untuk membandingkan perbedaan hasil belajar pada kedua kelas.

\section{HASIL DAN PEMBAHASAN}

Hasil analisis data hasil belajar secara deskriptif terlihat bahwa nilai rata-rata yang diperoleh dari kelas eksperimen lebih tinggi dibandingkan dengan kelas kontrol, yaitu 78,07 untuk kelas eksperimen dan 72,79 untuk kelas kontrol. Sedangkan nilai tertinggi pada kelas eksperimen adalah 87 dan nilai terendah 53. Sementara nilai tertinggi untuk kelas kontrol yaitu 83 dan nilai terendah 45 .

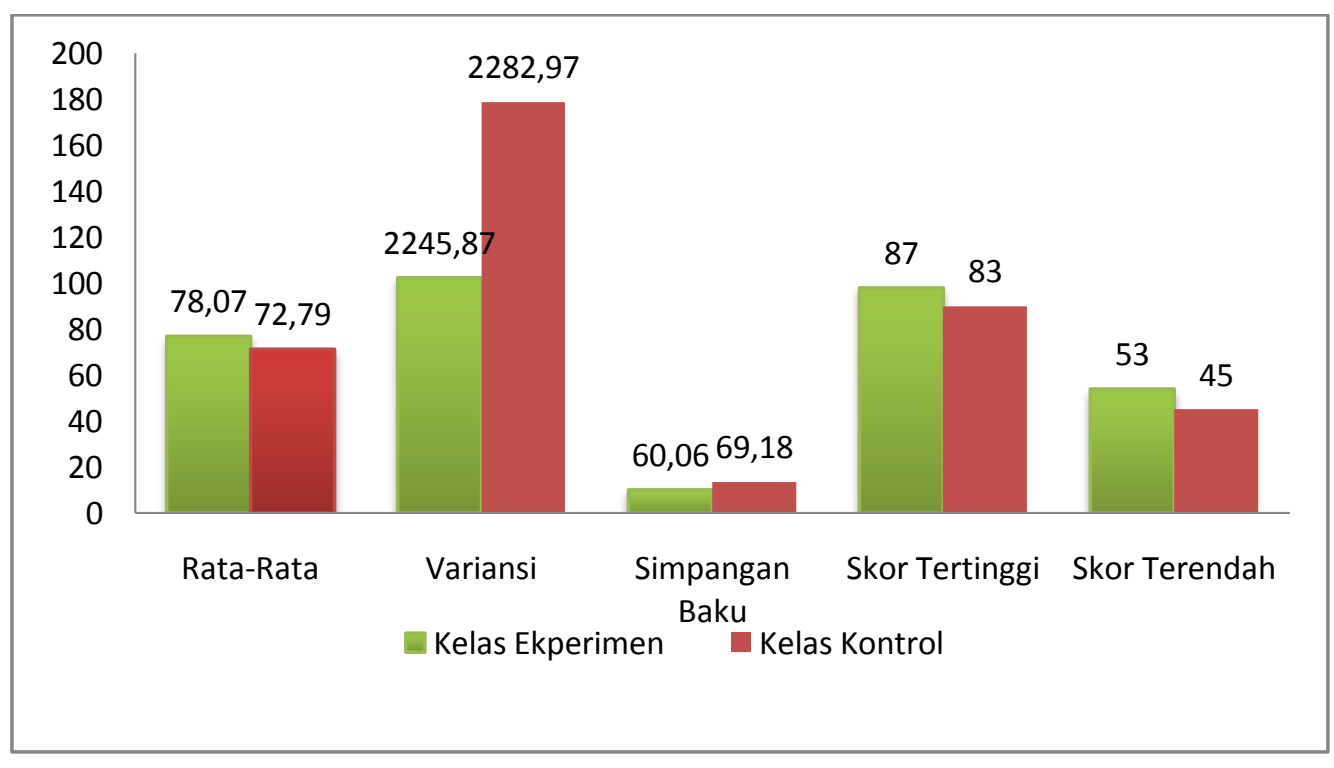

Gambar 1. Data Hasil Belajar Biologi Siswa 
Selain itu, jika dilihat dari nilai variansi kelas eksperimen lebih rendah dari pada variansi kelas kontrol. Hal ini menunjukkan bahwa hasil belajar biologi siswa kelas eksperimen secara umum lebih seragam dibanding kelas kontrol dengan presentase ketuntasan kelas eksperimen sebesar 78\% dan kelas kontrol sebesar 37,5\%.

Berdasarkan Gambar 2 di atas, adalah tabel perbandingan antara kelas eksperimen dan kelas kontrol, berdasarkan hasil penelitian yang telah dilakukan dapat terlihat bahwa persentase ketuntasan siswa pada kelas eksperimen lebih tinggi dari pada kelas kontrol, pada kelas eksperimen persentase siswa yang tuntas yaitu $86,7 \%$, yang tidak tuntas $14,3 \%$.

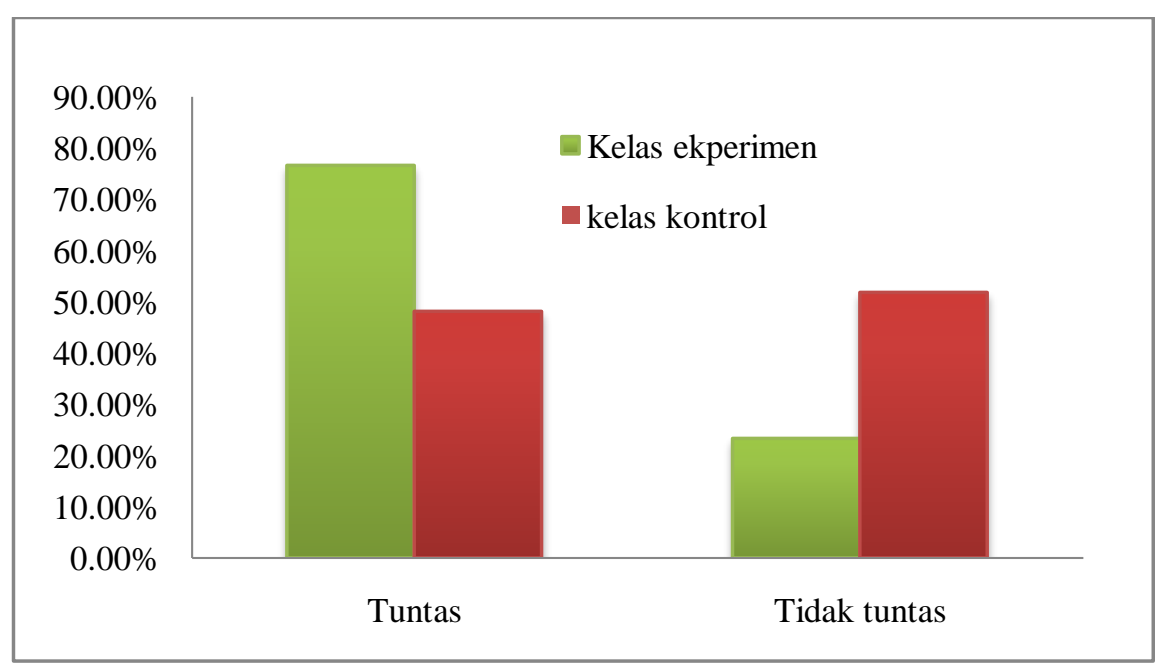

Gambar 2. Persentase Ketuntasan Hasil Belajar Siswa

Sedangkan pada kelas kontrol yang tuntas 4,4\%, dan tidak tuntas 55,6\%. Hal ini menandakan bahwa hasil belajar biologi siswa pada kelas eksperimen dengan penerapan strategi small group discussion (SGD) dengan pembelajaran kooperatif tipe talking stick berbantuan handout lebih baik dari pada hasil belajar biologi siswa pada kelas kontrol yang menerapkan metode konvensional berbantuan handout.

1. Uji Normalitas

Pada kelas eksperimen diperoleh $L_{0}=0.137$ dan berdasarkan tabel nilai kritik l untuk uji lilliefeors untuk $\alpha=0,05$ dengan jumlah siswa 30 orang diperoleh $\mathrm{L}_{\text {tabel }}=0,152$. Jika $L_{0}<L_{\text {tabel }}(0,137<0,152)$, maka dapat disimpulkan bahwa kelas eksperimen berdistribusi normal. Sedangkan kelas kontrol diperoleh $L_{0}=0.092$ dan berdasarkan tabel nilai kritik $l$ untuk uji lilliefeors untuk $\alpha=0,05$ dengan jumlah siswa 27 orang diperoleh $\mathrm{L}_{\text {tabel }}=0,152$. Jika $\mathrm{L}_{0}<\mathrm{L}_{\text {tabel }}(0,09<0,152)$, maka dapat disimpulkan bahwa kelas kontrol berdistribusi normal. 


\section{Uji Homogenitas}

Berdasarkan uji homogenitas data nilai hasil belajar biologi siswa adalah 0.57 berdasarkan tabel $f$ diperoleh nilai $f_{1-\frac{\alpha}{2}}\left(v_{1}, v_{2}\right)$ adalah 0.526316 dan nilai $f_{\frac{\alpha}{2}}\left(v_{1}, v_{2}\right)$ adalah 1.90 karena $\boldsymbol{f}_{1-\frac{\alpha}{2}}\left(\boldsymbol{v}_{1}, \boldsymbol{v}_{2}\right)<f<f_{\frac{\alpha}{2}}\left(v_{1}, v_{2}\right)$ atau $0.52<0.57<1.90$ Dengan demikian dapat disimpulkan bahwa data sampel memiliki variansi yang homogen.

3. Uji Hipotesis

Berdasarkan hasil perhitungan dengan uji-t didapat harga $t_{\text {hitung }}=1,87$ sedangkan $t_{\text {tabel }}=$ 1,645 pada taraf nyata $\alpha=0,05$. Berarti $t_{\text {hitung }}>t_{\text {tabel }}$ dimana $1,878>1,64$, berarti $\mathrm{H}_{0}$ ditolak dan $\mathrm{H}_{1}$ diterima. dapat disimpulkan bahwa hasil belajar Biologi siswa dengan penerapan strategi small group discussion dengan pembelajaran kooperatif tipe talking stick berbantuanhandoutlebih baik dari pada hasil belajar biologi siswa yang menggunakan metode diskusi handout berbantuan handout.

Berdasarkan hasil penghitungan dan analisa hasil belajar biologi siswa, didapatkan bahwa hasil belajar biologi siswa pada kelas eksperimen lebih baik jika dibandingkan dengan kelas kontrol. Hal ini disebabkan karena pada kelas eksperimen diberikan perlakuan dengan penerapan strategi small group discussion (SGD) dengan pembelajaran kooperatif tipe talking stick berbantuan handout sedangkan pada kelas kontrol hanya menggunakan metode konvensional berbantuan handout. Ada beberapa hal yang menyebabkan hasil belajar biologi siswa menjadi lebih baik dengan penerapaan strategi small group discussion (SGD) dengan pembelajaran kooperatif tipe talking stick berbantuan handout dibandingkan dengan hasil belajar siswa yang menggunakan metode konvensionalberbantuan handout.

Zuriati (2018) melaporkan bahwa peningkatan prestasi belajar di setiap siklusnya tidak terlepas dari penerapan metode pembelajaran Small Group Discussion.Dalam pembelajaran ini, peserta didik dibimbing secara aktif untuk berdiskusi dengan teman kelompoknya, menjawab pertanyaan, aktif memberikan tanggapan, serta aktif dalam mencari sumber belajar. Hal inilah yang memberikan dampak pada peningkatan prestasi belajar peserta didik. Hal ini sejalan dengan penelitian Cristiani dan Mintohari (2014) melalui penerapan Metode Small Group Discussion dengan Model Cooperative Learning proses pembelajaran menjadi berpusat pada siswa sehingga meningkatkan aktivitas siswa dalam proses pembelajaran. Adanya peningkatan aktivitas siswa tersebut dapat meningkatkan hasil belajar siswa karena siswa menjadi berperan aktif menemukan sendiri, konsep pembelajaran yang hendak dicapai melalui langkah - langkah pembelajaran yang berpusat pada siswa. 
Selanjutnya, pada awal pembelajaran peneliti telah menjelaskan bahwa di akhir pembelajaran akan diadakan pembelajaran talking stick (tongkat berbicara) dimana siswa melakukan pengoporan tongkat yang diiringi sebuah musik, saat musik berhenti dan stik berada ditangan salah satu siswa maka siswa tersebut yang menjawab pertanyaan yang dibacakan oleh guru, jadi setiap siswa harus siap untuk mengikuti talking stick pada akhir pembelajaran, sehingga siswa lebih tertantang dan termotivasi untuk belajar dengan sunggguh-sungguh. Talking stick yang dilakukan yaitu siswa berlomba-lomba untuk menjawab pertanyaan yang diberikan dengan benar dalam waktu yang menegangkan karena disanalah diuji konsentrasi siswa dalam belajar. Sehingga pada saat talking stick, antusiasme siswa sangat terlihat, diantaranya siswa yang merasa jawabannya salah tetap semangat ketika melakukan pengoporan tongkat.

Berdasarkan hasil penelitian Siregar, (2015) perbedaan hasil belajar siswa signifikan antara kelas eksperimen yang diajarkan dengan talking stick dan kelas kontrol yang diajarkan dengan konvensional. Hasilnya memperlihatkan bahwa terdapat perbedaan hasil belajar siswa diantara dua kelas tersebut, model pembelajaran talking stick memberikan pengaruh yang signifikan terhadap hasil belajar siswa dimana siswa memperoleh nilai yang lebih baik dibandingkan dengan siswa di kelas metode konvensional. Hal ini sejalan dengan penelitian Marni dan Yusuf (2015) bahwa melalui hasil peneilitian ini menunjukkan bahwa metode talking stick memiliki dampak positif dalam meningkatkan prestasi belajar siswa, baik di dalam proses pembelajaran maupun setelah menjawab tes.

Handout berfungsi untuk membantu pendengar agar tidak perlu mencatat, dan sebagai pendamping penjelasan guru. Dengan adanya handout sebagai suplemen diharapkan dapat menunjang keberhasilan proses pembelajaran. Handout sangat bermanfaat bagi siswa karena dapat digunakan sebagai sumber materi pada kegiatan diskusi (Ernawati 2014), dan membantu siswa dalam belajar secara mandiri di rumah sebelum pelajaran yang dilakukan di kela (Trianto, 2010). Handout dapat juga dilengkapi dengan kegiatan praktikum dan evaluasi sehingga proses belajar semakin aktif dan kontekstual (Wulandari et al., 2016).

\section{KESIMPULAN}

Berdasarkan hasil penelitian yang telah dilaksanakan, diperoleh bahwa hasil belajar biologi siswa dengan menggunakan pembelajaran kooperatif small group discussion (SGD) dengan talking stick berbantuan handoutlebih baik dari pada hasil belajar siswa dengan 
menggunakan pembelajaran konvensional berbantuan handout pada pembelajaran biologi di kelas VIII SMPN 5 Padang Panjang dengan hasil yang diperoleh bagi siswa kelas eksperimen sebesar $78 \%$ dan kelas kontrol sebesar 37,5\%.

\section{REFERENSI}

Christiani, A., dan Mintohari, 2014. Penerapan Metode Small Group Discussion Dengan Model Cooperative Learning Untuk Meningkatkan Hasil Belajar Siswa Di Sekolah Dasar. JPGSD, Vol. 2 (2):1-11.

Ernawati, H., 2014. Pengaruh Small Group Discussin Terhadap Pengetahuan Tentang Dismenore Pda Siswi SMPN 1 Dolopo. Jurnal Florence, VII(1): 47-51.

Hasibuan, J.J. dan Moedjiono, 2008. Proses Belajar Mengajar. Remaja Rosdakarya. Bandung.

Ismawati, N., dan Hindarto, N., 2011. Penerapan Model Pembelajaran Kooperatif Dengan Pendekatan Struktural Two Stay Two Stray Untuk Meningkatkan Hasil Belajar Siswa Kelas X SMA N. Jurnal Pendidikan Fisika Indonesia, Vol. 7 (1): 38-41.

Marni, dan Yusuf, M. T., 2015. Penggunaan Metode Talking Stik Untuk meningkatkan Maharat Al-Kalam Dalam Mata Pelajaran Bahasa Arab. Auladuna, Vol. 2(1): 87-103.

Pambudi, R. L. I., 2017. Penerapan Model Pembelajaran Talking Stick Untuk Meningkatkan Hasil Belajar Matematika Pada Siswa Kelas IV SDN Suryodiningratan II Tahun Ajaran 2015-2016. Basic Education. Vol. 6 (1):70-80.

Prastowo, A., 2011. Panduan Kreatif Membuat Bahan Ajar Inofatif. Diva Press. Yogyakarta.

Purwanti, S., 2017. Penerapan Small Group Discussion Untuk Meningkatkan Hasil Belajar Dan Keaktifan Mahasiswa PGSD UAD. Jurnal Dialektika Jurusan PGSD, Vol. 7(1):10-19.

Siregar, S., 2015. Pengaruh Pembelajaran Talking Stick Terhadap Hasil Belajar Dan Aktivitas Visual Siswa Pada Konsep Sistem Indra. Jurnal Biotik, Vol, 13(2): 100-106.

Sugiyono, 2008. Metode Penelitian Pendidikan Kuantitatif, kualitatif dan R\&D. Alfabeta. Bandung .

Suherman, 2006. Strategi Mengajar Belajar Matematika. Universitas Negeri Malang. Malang.

Suprijono, 2011. Cooperatife Learning Teori dan Aplikasi PAIKEM. Pustaka Pelajar. Yogyakarta.

Trianto. 2010. Mendesain Model Pembelajaran Inovatif -Progresif. Kencana. Jakarta.

Wulandari, S., Suarsini, E., dan Ibrohim, 2016. Pemanfaatan Sumber Belajar Handout Bioteknologi Lingkungan Untuk Meningkatkan Pemahaman Konsep Mahasiswa S1 Universitas Negeri Malang. Jurnal Pendidikan, Vol.1, (5):881-884

Zuriati, 2018. Penerapan Metode Small Group Discussion Dalam Pembelajaran Pendidikan Agama Islam: Dampak Terhadap Peningkatan Prestasi Belajar Peserta Didik Kelas X SMA. Sosiohumaniora. Vol.4(1):71-77. 